\title{
Invasive Ductal and Lobular Carcinoma
}

National Cancer Institute

\section{Source}

National Cancer Institute. Invasive Ductal and Lobular Carcinoma. NCI Thesaurus. Code C7688.

An invasive ductal breast carcinoma associated with a lobular carcinomatous component. The lobular carcinomatous component may be in situ or invasive. 